\title{
DEFLUORIDATION OF WATER USING TAMARIND (TAMARINDUS INDICA) FRUIT COVER: KINETICS AND EQUILIBRIUM STUDIES
}

\author{
NEDUNURI PHANI KUMAR ${ }^{1}$, NADAVALA SIVA KUMAR², ABBURI KRISHNAIAH ${ }^{1, *}$ \\ ${ }^{\prime}$ Biopolymers and Thermophysical Laboratory, Department of Chemistry, Sri Venkateswara University, Tirupati - 517 502, India \\ ${ }^{2}$ Department of Safety Environmental System Engineering, Dongguk University, Gyeongju 780-714, Republic of Korea
}

(Received: October 11, 2011 - Accepted: June 8, 2012)

\begin{abstract}
In the present study defluoridation of water was conducted using Tamarind fruit cover (TNFC) as a natural adsorbent in virgin and acid treated forms. Defluoridation of water was studied under batch equilibrium and column flow experimental conditions. The adsorbents were characterized by FTIR, SEM, Pycnomatic ATC techniques. The effect of experimental variables such as initial concentration of fluoride, effect of $\mathrm{pH}$, contact time, co-ions and amount of adsorbent dosage was evaluated. The study was also extended to real field water samples. The equilibrium data were used to study the kinetics of defluoridation process and also to predict the isotherms applicable to the adsorption process. The maximum monolayer adsorption capacity of virgin TNFC and treated TNFC sorbents as obtained from the Langmuir adsorption isotherm was found to be $4.14 \mathrm{mg} / \mathrm{g}$ and $6.11 \mathrm{mg} / \mathrm{g}$ of fluoride. The column flow adsorption data were utilized to obtain break through curves.
\end{abstract}

Keywords: Defluoridation, Adsorption, Bioadsorbent, Kinetics, Isotherms modeling.

\section{INTRODUCTION}

Fluoride is an essential microelement for human health. Smaller quantities in the order of $1 \mathrm{mg} / \mathrm{L}$ in the ingested water are usually beneficial as the rate of occurrence of dental carries decreases, particularly among children. ${ }^{1}$ On the other hand due to its strong electro negativity; fluoride is attracted by positively charged calcium ions in teeth and bones. Excessive intake results in pathological changes in teeth and bones, such as mottling of teeth or dental fluorosis followed by skeletal fluorosis. ${ }^{2}$ Fluoride may cause an increase in the concentration of thyroid stimulating hormone (TSH) and a decrease in the concentration of T3 and T4 hormones in the thyroid gland resulting in hypothyroidism. ${ }^{3,4}$ Excess fluoride in drinking water is prevalent in all of the Rift Valley Regions of the country. ${ }^{5}$ According to the World Health Organization (WHO) permissible limit for fluoride in drinking water is 1 $\mathrm{mg} / \mathrm{L}$, whereas, the United States Public Health Service (USPHS) has set a range of allowable concentrations for fluoride in drinking water for a region depending on its climatic conditions because the amount of water consumed and consequently the amount of fluoride ingested being influenced primarily by the air temperature. ${ }^{1,6}$ Lesan suggested a limit of fluoride in drinking water as low as $0.6 \mathrm{mg} / \mathrm{L}$ in tropical conditions. ${ }^{7}$ Hence, it is necessary to bring down the fluoride concentration within the permissible limit of $1.5 \mathrm{mg} / \mathrm{L}$ as defined by the international guidelines. ${ }^{8}$ Several methods have been used to remove fluorides from water, namely adsorption, ${ }^{9-11}$ precipitation, ${ }^{12}$ electro dialysis, ${ }^{13}$ ion exchange ${ }^{14}$ and electrochemical methods, ${ }^{15,16}$ were developed to remove the fluoride from water. Among the existing techniques, adsorption is regarded as an important cost-effective technique in the developing countries where the impact of this issue is maximum. This technique is most widely used for the removal of excess fluoride from the aqueous solution.

In recent years, the use of low cost adsorbents has been investigated by many to remove fluoride from water. Such materials include: hydroxyl apatite, calcite, fluorspar, quartz, ${ }^{17}$ flyash, ${ }^{18}$ silica gel, ${ }^{19}$ bone char ${ }^{20}$ spent catalyst, ${ }^{21}$ zeolites, ${ }^{22}$ red mud, ${ }^{23}$ bentonite, ${ }^{24}$ clay chips,${ }^{25}$ lateritic soils, ${ }^{26}$ nano-alumina, ${ }^{27}$ aluminum hydroxide coated rice husk ash, ${ }^{28}$ waste mud, ${ }^{29}$ diatomaceous earth and other related materials. ${ }^{30,31}$ However, the applicability of these low cost methods is limited either due to their low efficiency or lack of public acceptance. Therefore, it is of paramount importance to identify materials with high rate of removal, economically, socially and technically feasible for applications in rural communities. The successful and cost-effective removal of contaminants from wastewater, by adsorption techniques, demands the optimal operation of the adsorption units. Fluoride removal from water using activated and $\mathrm{MnO}_{2}$ coated tamarind fruit (Tamarindus indica) shell: Batch and column studies were studied by Sivasankar et al..$^{32}$ Similarly, Sriramachari ${ }^{33}$ and Maruthamuthu and Venkatanarayanareddy ${ }^{34}$ reported the binding of fluoride by tamarind gel.

The aim of this work is to examine and determine the potential application of Tamarind fruit cover in its virgin and acid treated forms in removing fluoride ion from aqueous medium under batch equilibrium and column flow experimental conditions. Further this biosorbents were characterized by FTIR,
SEM and surface area analysis to understand the surface morphology.

\section{MATERIALS AND METHODS}

\section{Adsorbate}

Fluoride stock solution was prepared by dissolving $2.21 \mathrm{~g}$ of anhydrous sodium fluoride $(99.0 \% \mathrm{NaF}, \mathrm{AR}, \mathrm{BDH}$ chemical Ltd) in $1000 \mathrm{~mL}$ distilled water in volumetric flask. Standard and fluoride spiked samples at a required concentration range were prepared by appropriate dilution of the stock solution with double distilled water.

\section{Analytical Method}

A pH/IES meter (Orion Model, EA 940 Expandable Ion Analyzer) equipped with combination fluoride-selective electrode (Orion model 9609) was employed for the measurement of fluoride ion concentration. The method of direct potentiometry was used, where the concentration of fluoride can be read directly. The $\mathrm{pH}$ was measured with $\mathrm{pH} /$ ion meter using $\mathrm{pH}$ glass electrode. The meter was calibrated whenever the measurements were made by using $\mathrm{pH}$ calibration buffer.

\section{Preparation of biosorbent}

\section{Tamarind fruit cover}

Tamarind fruit cover is brittle, easily cracked shell of ripe tamarind pod that separates out from the fruit. This is available in plenty as a waste by product of tamarind pulp industry. Tamarind fruit covers (TNFC) were obtained from the ripe tamarind fruit. They are easily broken, brown in colour and these were collected locally from Tirupati town, A.P., India. It was washed with distilled water for discoloration and dried in an oven at $100^{\circ} \mathrm{C}$ for half an hour. The dried biomass was powdered and sieved to get produced uniform sized powders. Half of the virgin biomass was pretreated with $1 \mathrm{M} \mathrm{HCl}$ in order to examine the possible increase in adsorption capacity of TNFC. Fluoride adsorption investigations were made on TNFC (virgin) as well as TNFC (treated).

\section{Pre-treatment of the biosorbent}

The pre-treatment of TNFC is carried out to increase the metal uptake efficiency. The virgin TNFC was soaked in $1 \mathrm{M} \mathrm{HCl}$ for $24 \mathrm{hrs}$ and kept on the water bath $\left(70^{\circ} \mathrm{C}\right)$ for half an $\mathrm{hr}$. It is cooled and is neutralized with $50 \mathrm{ml}$ of $1 \mathrm{~N}$ $\mathrm{NaOH}$. Finally it was washed with distilled water several times and dried in an oven at $80^{\circ} \mathrm{C}$ for $6 \mathrm{hrs}$ and cooled at room temperature in desiccators.

\section{Batch adsorption studies}

Stock solution of fluoride of $1000 \mathrm{mg} / \mathrm{L}$ was diluted to get desired concentration $(5,10,15,20$ and $25 \mathrm{mg} / \mathrm{L}$ of fluoride). Equilibrium batch adsorption experiments were carried out with known weight $(500 \mathrm{mg})$ of adsorbent and $100 \mathrm{~mL}$ of fluoride stock solution of desired concentration at optimum $\mathrm{pH}$ in $125 \mathrm{~mL}$ stopper bottles. The bottles were shaken in a temperature controller water bath $\left(25 \pm 1^{\circ} \mathrm{C}\right)$ at $200 \mathrm{rpm}$ for $2 \mathrm{hrs}$ to reach equilibrium of the solid-solution mixture. After attaining equilibrium, the biosorbent was separated by filtration and the aqueous-phase concentration of fluoride was analyzed with ion-selective electrode (I.S.E. 96-09) using total ionic strength adjustment buffer (TISAB) solution. TISAB consists of 1 
mole of sodium chloride $(\mathrm{NaCl}), 1$ mole of acetic acid $\left(\mathrm{CH}_{3} \mathrm{COOH}\right), 4.0 \mathrm{~g}$ of 1, 2-cyclo-hyxylene dinitro tetra acetic acid (CDTA) and sufficient sodium hydroxide $(\mathrm{NaOH})$ to give a final $\mathrm{pH}$ in the range of 5 to 5.5 in $1.0 \mathrm{~L}$ of solution and to eliminate the interference effect of complexing ions. In all cases, the amount of complexed fluoride, other than $\mathrm{NaF}$ and $\mathrm{HF}$ species, was found to be insignificant.

The equilibrium uptake capacity for each sample was calculated according to mass balance on fluoride ions.

$$
Q_{e}=\frac{C_{i}-C_{e}}{m} V
$$

where $C_{\mathrm{i}}$ and $C_{e}(\mathrm{mg} / \mathrm{L})$ were the initial and equilibrium fluoride ion concentrations respectively, ' $m$ ' was the mass of adsorbent used $(\mathrm{g})$ and ' $V$ ' (L) was volume of the solution. Experiments were conducted with fluoride ion solution in the absence of adsorbent and it was found that there was no fluoride adsorption by the walls of the container.

Column adsorption studies

Column flow adsorption experiments were conducted in a glass column of about $2.5 \mathrm{~cm}$ internal diameter and $10 \mathrm{~cm}$ length. All experiments were carried out at temperature of $25 \pm 1{ }^{\circ} \mathrm{C}$. The column was filled with a known weight of the adsorbent while tapping the column so that the column was without significant voids. The adsorbate solution was allowed to flow through the column at a constant flow rate $(2 \mathrm{~mL} / \mathrm{min})$ throughout the experiment. The $\mathrm{pH}$ of the inlet solution was adjusted to 6 for both virgin and treated biosorbents at the start of the experiment. The effluent solution was collected at different time intervals and the concentration of fluoride in the effluent solution was monitored by the Ion-selective electrode method. The solutions were diluted with TISAB appropriately prior to analysis. Samples at 10 minute time intervals from the start of the experiment were collected for analysis. Breakthrough curves for each adsorbent individually were obtained by plotting the volume of solution against the ratio of the concentration of effluent at any time $\left(\mathrm{C}_{\mathrm{e}}\right)$ to that of the inlet solution $\left(\mathrm{C}_{0}\right), \mathrm{C}_{\mathrm{e}} / \mathrm{C}_{0}$.

\section{Desorption studies}

The solvent elution method was used to remove the adsorbed fluoride from virgin and treated TNFC. After the column was exhausted, it was drained off from the remaining aqueous solution by pumping air through it. Desorption of solute from loaded adsorbents was carried out by using $0.1 \mathrm{M} \mathrm{NaOH}$ solution as eluent. The eluent was pumped into the column at a fixed flow rate of 1.0 $\mathrm{mL} / \mathrm{min}$ at temperature of $25 \pm 1^{\circ} \mathrm{C}$. From the start of the experiment effluent samples at different intervals were collected at the bottom of the column for analysis. After the regeneration, the adsorbent column was washed with distilled water to remove sodium hydroxide from the column before the influent fluoride solution was reintroduced for the subsequent adsorption-desorption cycles. Adsorption-desorption cycles were performed thrice using the same bed to check the sustainability of the bed for repeated use.

\section{RESULTS AND DISCUSSION}

\section{Characterization of biosorbents}

Porosity of biosorbent

The influence of the surface properties on the extent of adsorption was evaluated by measuring pore volume and pore density. Porosity was one of the factors that influence the activity and physical interaction of solids with liquids and gases. Percentage porosity was measured by taking one gram of the biosorbent and those values are presented in Table 1. Among the two adsorbents, the treated TNFC possesses a higher \% porosity (30.85) when compared to that of virgin TNFC (21.70).

Table 1. Porosity of biosorbent.

\begin{tabular}{|c|c|c|c|}
\hline Biosorbent & $\begin{array}{c}\text { Pore volume } \\
\left(\mathrm{cm}^{3} / \mathrm{g}\right)\end{array}$ & $\begin{array}{c}\text { Pore density } \\
\left(\mathrm{g} / \mathrm{cm}^{3}\right)\end{array}$ & Porosity $(\%)$ \\
\hline $\begin{array}{c}\text { Tamarind nut fruit } \\
\text { covers TNFC (virgin) }\end{array}$ & 0.14 & 7.14 & 21.70 \\
\hline $\begin{array}{c}\text { Acid treated Tamarind } \\
\text { fruit nut cover TNFC } \\
\text { (treated) }\end{array}$ & 0.21 & 4.86 & 30.85 \\
\hline
\end{tabular}

Fourier Transform Infrared (FTIR) Studies

FTIR spectra of tamarind fruit cover (TNFC) in its natural and acid treated forms before and after fluoride adsorption are shown in Fig. 1. Fig. 1 (a), (b), (c), (d) show FTIR spectra of virgin TNFC, fluoride loaded virgin TNFC, treated TNFC, and fluoride loaded treated TNFC respectively. FTIR spectra in Fig. 1. Show peaks at $3550-3400 \mathrm{~cm}^{-1}$ indicating the presence of $-\mathrm{OH}$ groups. The absorption bands around $1650 \mathrm{~cm}^{-1}$ indicate presence of amide group, and at $1750 \mathrm{~cm}^{-1}$ indicate $\mathrm{C}=\mathrm{O}$ stretching. In the spectra of fluoride loaded virgin TNFC and treated TNFC the strong peak around $1000 \mathrm{~cm}^{-1}$ indicates the C-F bond stretching. ${ }^{35,36}$ The peaks present at $800-700 \mathrm{~cm}^{-1}$ indicate the presence of aromatic ortho disubstituted heterocyclic molecules, but these peaks are absent in the spectra of acid treated biosorbent (Fig 1. (c), (d)). This indicates that there is a possibility of ring cleavage..$^{37} \mathrm{~A}$ similar work was carried out by Sivasankar et al. ${ }^{32}$ for fluoride removal. The reduction in the peak intensities are observed in the spectra of treated TNFC before and after fluoride adsorption compared to virgin TNFC, which may be due to the deformation of the characteristic bands.

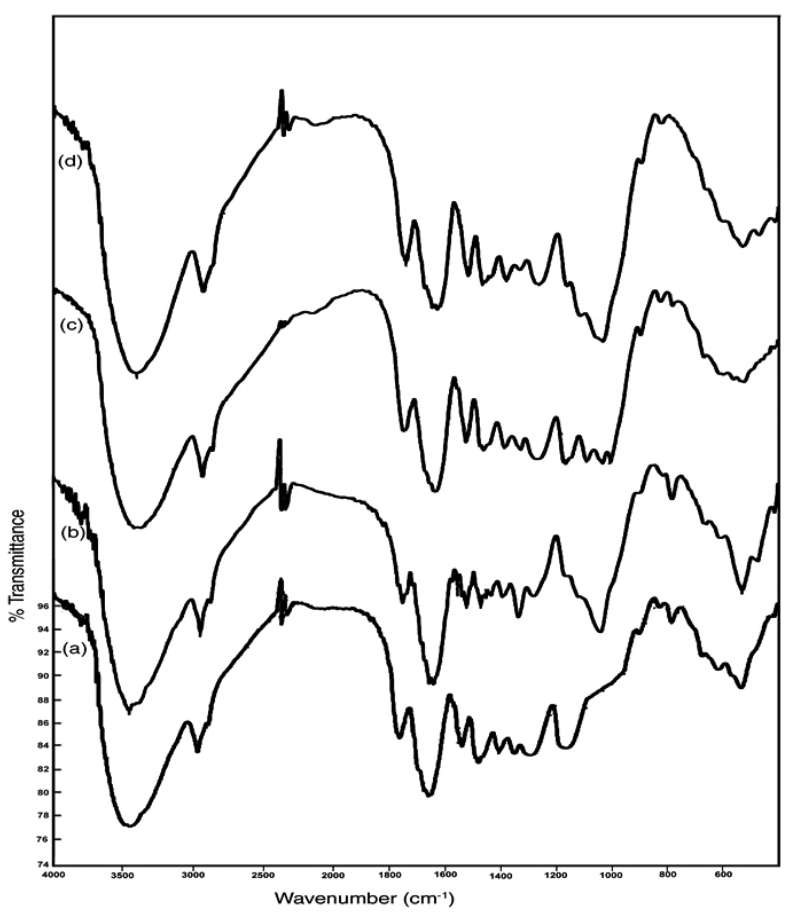

Figure 1. FTIR spectra of (a) TNFC virgin form (b) TNFC virgin form loaded with fluoride, (c) TNFC acid treated form, (d) TNFC acid treated form loaded with fluoride.

\section{Scanning Electron Microscopic (SEM) Studies}

SEM images of the biosorbents before and after fluoride sorption of virgin TNFC are shown in Fig. 2(a) and (b) respectively. The respective SEM images of acid treated TNFC before and after adsorption are shown in Fig. 2(c) and (d) respectively. The SEM of virgin TNFC shows the surface texture and porosity of the adsorbent with holes and small openings on the surface. The surface morphology of virgin TNFC has changed due to fluoride adsorption in Fig. 2(b). The porous nature of acid treated TNFC is clearly evident from the SEM micrograph as shown in Fig. 2(c). It can be observed that there is a change in the morphology of the TNFC (acid treated) after fluoride adsorption Fig. 2(d).

Effect of $\mathrm{pH}$

The $\mathrm{pH}$ of the aqueous solution plays an important role in controlling the adsorption at the water adsorbent interface. ${ }^{38}$ Therefore the adsorption of fluoride on TNFC was examined in the $\mathrm{pH}$ range 1-8 with initial fluoride concentration of $10 \mathrm{mg} / \mathrm{L}$ at $25 \pm 1^{\circ} \mathrm{C}$. The results are presented in Fig. 3. The $\mathrm{pH}$ of the working solution is controlled by adding $0.1 \mathrm{M} \mathrm{HCl}$ or $0.1 \mathrm{M} \mathrm{NaOH}$ solution. It can be inferred that fluoride removal increase with increasing $\mathrm{pH}$ until $\mathrm{pH}$ 6. The maximum defluoridation capacity is $1.48 \mathrm{mg} / \mathrm{g}$ for TNFC at $\mathrm{pH}$ 6. As the $\mathrm{pH}$ of the solution is further increased the adsorption capacity is decreases to $0.78 \mathrm{mg} / \mathrm{g}$ at $\mathrm{pH} 8$ for TNFC. Similar results are observed by Karthikeyan et al. ${ }^{39}$ when activated alumina was used as sorbent. This can be explained on the basis of the change in surface charge of the adsorbent. It is well established that the surface is highly protonated in acidic medium and therefore maximum fluoride removal in acidic medium is attributed to the gradual increase in attractive force between positively charged surface and 
negatively charged fluoride ions. However, the amount of fluoride adsorbed decreases and this can be attributed to the formation of weak hydrofluoric acid. ${ }^{40,4}$ Lower defluoridation capacity in alkaline medium can be explained by the fact that the surface acquires negative charge in alkaline $\mathrm{pH}$ and hence there is repulsion between the negatively charged surface and fluoride.

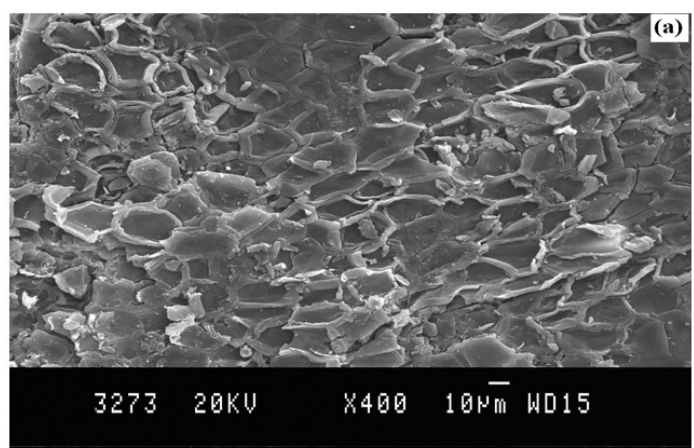

(a)

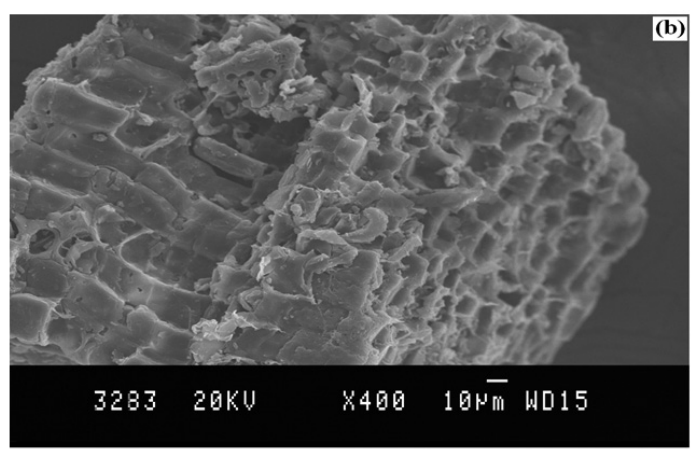

(b)

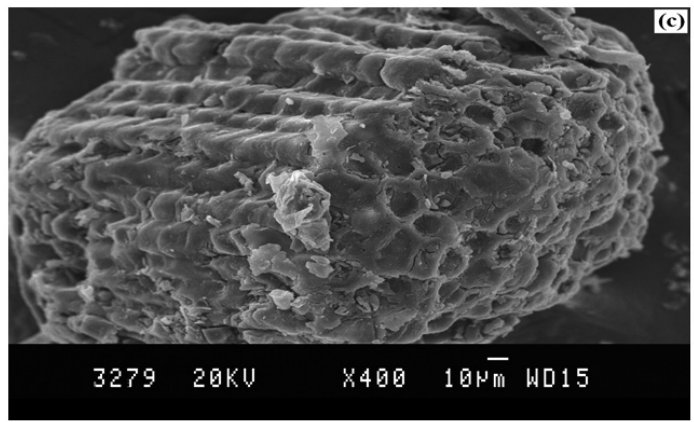

(c)

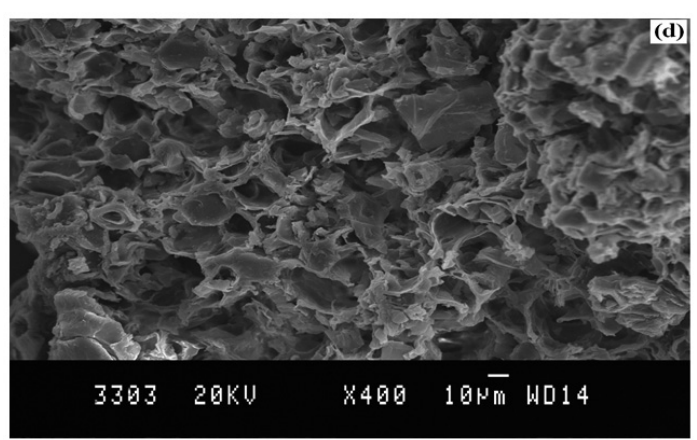

(d)

Figure 2. SEM images of (a) TNFC virgin form (b) TNFC virgin form loaded with fluoride, (c) TNFC acid treated form, (d) TNFC acid treated form loaded with fluoride.

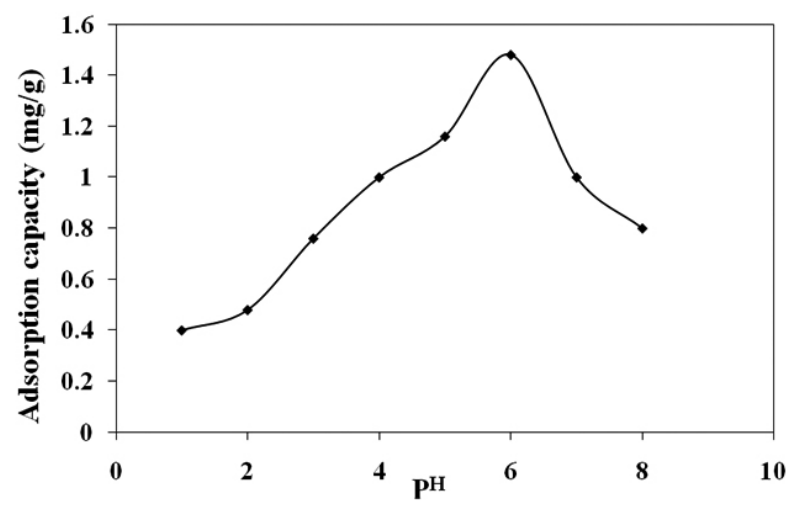

Figure 3. Effect of pH on biosorption of fluoride on TNFC.

\section{Effect of adsorbent dosage}

The effect of adsorbent dose on the removal of fluoride in solution at optimum pH 6 is shown in Fig. 4. The amount of adsorbent significantly influences the extent of fluoride adsorption. This increase in loading capacity is due to the availability of higher number of fluoride ions per unit mass of adsorbent, i.e. higher fluoride/adsorbent ratio. It can also be seen that the fluoride removal markedly increased up to adsorbent dose of $0.7 \mathrm{~g}$ due to increase in adsorbent/fluoride ratio, however further increase in adsorbent dose not show any appreciable improvement in fluoride removal. This may be because of the very low equilibrium concentration of fluoride, i.e. driving force responsible for adsorption becomes negligible.

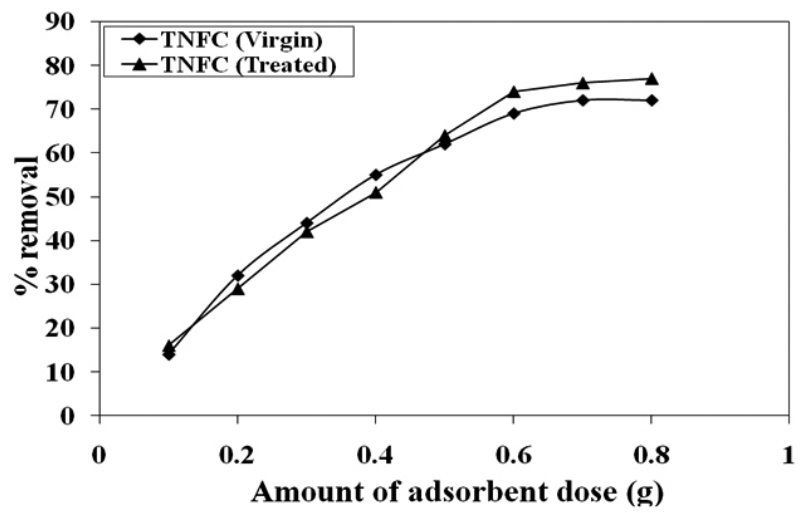

Figure 4. Effect of adsorbent dosage on adsorption of fluoride on TNFC (virgin) and TNFC (treated).

\section{Adsorption Kinetics}

The prediction of biosorption rate gives important information for designing batch biosorption systems. The adsorption data at different adsorbate concentrations were used to understand the dynamics of the adsorption process. Different kinetic models including the pseudo-first-order and pseudo-secondorder and were applied to the experimental data to predict the adsorption kinetics. The rate constant $k_{l}$ for sorption of fluoride was obtained from pseudofirst-order rate equation, ${ }^{42,43}$

$$
\log \left(Q_{e}-Q_{t}\right)=\log Q_{e}-\left(\frac{k_{1}}{2.303}\right) t
$$

where $\mathrm{Q}_{e}$ and $\mathrm{Q}_{\text {, }}$ (both in $\mathrm{mg} \mathrm{g}^{-1}$ ) are the amounts of fluoride adsorbed at equilibrium and at time ' $t$ ', respectively. Straight line plots of $\log \left(Q_{e}-Q_{\text {, }}\right)$ versus ' $t$ ' at different times indicate the validity of first order rate equation. The plots of $\log \left(Q_{e}-Q_{t}\right)$ versus ' $t$ ' are straight line with $\mathrm{R}^{2}>0.98$. The adsorption rate constant $k_{1}\left(\mathrm{~min}^{-1}\right)$, calculated from the slope of the plot are represented in Table 2 and 3 for initial concentrations of 5, 10, 15, 20 and $25 \mathrm{mg} / \mathrm{L}$, respectively.

The pseudo-second-order kinetic model in its integrated and linearized form has been used, ${ }^{44}$ 


$$
\frac{t}{Q_{t}}=\frac{1}{k_{2} Q_{e}^{2}}+\frac{1}{Q_{e}} t
$$

where $k_{2}(\mathrm{~g} / \mathrm{mg} / \mathrm{min})$ is the rate constant of the second-order equation, $Q_{t}(\mathrm{mg} / \mathrm{g})$ is the amount adsorbed at time $\mathrm{t}(\mathrm{min})$ and $Q_{e}$ is the amount adsorbed at equilibrium $(\mathrm{mg} / \mathrm{g})$. The rate constants $\left(k_{2}\right)$, calculated from the slopes of the plots of $t / Q_{t}$ vs. $t$ along with correlation coefficients and $Q_{e}$ values, are given in Table 2 and 3 for initial concentrations of $5,10,15,20$ and $25 \mathrm{mg} / \mathrm{L}$, respectively.

Table 2.Values of kinetic parameters for adsorption of fluoride on TNFC (virgin).

\begin{tabular}{|c|c|c|c|c|c|c|}
\hline \multirow{3}{*}{ Kinetic Model } & \multirow{2}{*}{ Parameter } & \multicolumn{5}{|c|}{ Initial concentration of Fluoride ion (mg/L) } \\
\cline { 3 - 7 } & & 5 & 10 & 15 & 20 & 25 \\
\hline \multirow{3}{*}{ Pseudo-first-order } & $\mathrm{K}_{1}$ & 0.041 & 0.030 & 0.028 & 0.027 & 0.025 \\
\cline { 2 - 7 } & $\mathrm{R}^{2}$ & 0.985 & 0.980 & 0.977 & 0.977 & 0.945 \\
\cline { 2 - 7 } & $\mathrm{SSE}$ & 0.569 & 0.014 & 0.011 & 0.286 & 0.394 \\
\hline \multirow{3}{*}{ Pseudo-second-order } & $\mathrm{K}_{2}$ & 0.046 & 0.046 & 0.047 & 0.047 & 0.041 \\
\cline { 2 - 7 } & $\mathrm{R}^{2}$ & 0.978 & 0.978 & 0.991 & 0.996 & 0.997 \\
\cline { 2 - 7 } & $\mathrm{Q}_{\mathrm{e}}$ & 0.779 & 1.401 & 2.138 & 2.910 & 3.892 \\
\hline \multirow{3}{*}{ Weber-Morris } & $\mathrm{SSE}$ & 0.021 & 0.008 & 0.002 & 0.001 & 0.001 \\
\cline { 2 - 7 } & $\mathrm{K}_{\mathrm{id}}$ & 0.079 & 0.08 & 0.100 & 0.101 & 0.113 \\
\cline { 2 - 7 } & $\mathrm{R}^{2}$ & 0.957 & 0.911 & 0.909 & 0.906 & 0.917 \\
\cline { 2 - 7 } & $\mathrm{C}$ & 0.050 & 0.369 & 0.905 & 1.578 & 2.269 \\
\hline
\end{tabular}

Table 3. Values of kinetic parameters for adsorption of fluoride on TNFC (treated).

\begin{tabular}{|c|c|c|c|c|c|c|}
\hline \multirow{3}{*}{ Kinetic Model } & \multirow{2}{*}{ Parameter } & \multicolumn{5}{|c|}{ Initial concentration of Fluoride ion (mg/L) } \\
\cline { 2 - 7 } & & 5 & 10 & 15 & 20 & 25 \\
\hline \multirow{3}{*}{ Pseudo-first-order } & $\mathrm{K}_{1}$ & 0.038 & 0.037 & 0.035 & 0.031 & 0.035 \\
\cline { 2 - 7 } & $\mathrm{R}^{2}$ & 0.951 & 0.995 & 0.984 & 0.964 & 0.913 \\
\cline { 2 - 7 } & $\mathrm{SSE}$ & 0.595 & 0.007 & 0.040 & 0.194 & 0.227 \\
\hline \multirow{3}{*}{ Pseudo-second-order } & $\mathrm{K}_{2}$ & 0.036 & 0.036 & 0.030 & 0.030 & 0.030 \\
\cline { 2 - 7 } & $\mathrm{R}^{2}$ & 0.999 & 0.997 & 0.998 & 0.990 & 0.998 \\
\cline { 2 - 7 } & $\mathrm{Q}_{\mathrm{e}}$ & 0.807 & 1.545 & 2.381 & 3.250 & 4.203 \\
\hline \multirow{3}{*}{ Weber-Morris } & $\mathrm{SSE}$ & 0.062 & 0.017 & 0.010 & 0.004 & 0.003 \\
\cline { 2 - 7 } & $\mathrm{K}_{\mathrm{id}}$ & 0.049 & 0.079 & 0.105 & 0.115 & 0.117 \\
\cline { 2 - 7 } & $\mathrm{R}$ & 0.887 & 0.899 & 0.899 & 0.914 & 0.925 \\
\cline { 2 - 7 } & $\mathrm{C}$ & 0.103 & 0.503 & 1.009 & 1.771 & 2.671 \\
\hline
\end{tabular}

The validity of both kinetic models was checked through the existence of linear relationships indicated by eqs. (2) and (3). In many cases the pseudofirst-order equation did not fit well to the experimental data over the entire range of contact time and was generally applicable over the initial stage of the adsorption processes. The pseudo-first-order kinetic process has been used for reversible adsorption with an equilibrium being established between liquid and solid phases, whereas, the second order kinetic model assumes that the rate limiting step may be chemisorptions. In many adsorbate-adsorbent systems, where both chemical and physical adsorption occurs, the adsorption data are well correlated by the pseudo-second-order equation. As a result, it is obvious from Table 2 and 3 that the entire kinetic data fitted well with pseudo-secondorder kinetic model, which is evident from the higher correlation coefficient values.

3.5. Weber-Morris model

The intra-particle diffusion equation, proposed by Weber-Morris, is expressed in the following form. ${ }^{45}$

$$
Q_{t}=K_{i d}{ }^{1 / 2}+C
$$

where $\mathrm{Q}_{\mathrm{t}}(\mathrm{mg} / \mathrm{g})$ is the amount adsorbed at time $\mathrm{t}(\mathrm{min})$ and $K_{i d}$ is the intra particle diffusion rate constant $(\mathrm{mg} / \mathrm{g} / \mathrm{min})$. C is the value of intercept which gives an idea about the boundary layer thickness, i.e. the larger intercept; the greater is the boundary effect. The slope of the plot of $Q_{t}$ against $t^{1 / 2}$ gives the value of the (figures not shown) intraparticle diffusion coefficient. If the correlation of the above variables gives straight line that passes through the origin, then it suggests that the intraparticle diffusion contributes predominantly in rate determining step. ${ }^{46}$ The initial portion of the curve gives a straight line, which implies during the initial time up to $10 \mathrm{~min}$, the adsorption process follows intraparticle diffusion. After this, surface adsorption may be the predominant mechanism of fluoride uptake. The unusual behavior is obtained due to the heterogeneous nature of TNFC surface. Therefore, the adsorption of fluoride onto TNFC takes place through surface adsorption as well as intraparticle diffusion. ${ }^{10}$

Fitness of the sorption kinetic models

The validity of kinetic models for fitting the sorption data was assessed through the calculation of sum of squares of the error (SSE). Lower values of SSE showed better fit to the sorption data and gave an indication of the sorption mechanism: 


$$
\mathrm{SSE}=\quad \sum \frac{\left(q_{t, e}-q_{t, m}\right)^{2}}{q_{t, e}^{2}}
$$

where $\mathrm{q}_{\mathrm{te}}$ and $\mathrm{q}_{\mathrm{t} \mathrm{m}}$ are the experimental sorption capacity of fluoride ions $(\mathrm{mg} / \mathrm{g})$ at time $\mathrm{t}$, and the corresponding value that is obtained from the kinetic models, respectively. SSE values of the pseudo-first-order, pseudosecond-order kinetic model and Weber-Morris method were computed and are summarized in Table 2 and 3. The model that gave the lowest SSE values was considered to be the best model for fluoride ion sorption onto TNFC (virgin) and TNFC (treated) and then, the mechanism of sorption could then be explained on the basis of that model. As shown in Table 2 and 3, the pseudo second-order kinetic model suggested a good correlation for the adsorption of fluoride on the TNFC (virgin) and TNFC (treated) contrast to the pseudo-first-order model and Weber-Morris method, so pseudo-second-order model is suitable for modeling the adsorption of fluoride on the TNFC (virgin) and TNFC (treated).

\section{Adsorption isotherm models}

The analysis of the sorption isotherms is important for design purposes. Therefore, the experimental data obtained were analyzed with well known sorption isotherm models namely, the Langmuir and Freundlich isotherms. Langmuir sorption isotherm assumes the monolayer coverage on a structurally homogeneous surface of the adsorbent.

The Langmuir isotherm model can be represented in the form,

$$
Q_{\mathrm{e}}=\frac{Q^{o} b C_{e}}{1+b C_{e}}
$$

where $C_{\mathrm{e}}$ is the concentration of fluoride $(\mathrm{mg} / \mathrm{L})$ at equilibrium, $Q^{0}$ is the monolayer capacity of the adsorbent $(\mathrm{mg} / \mathrm{g})$ and $b$ is the Langmuir adsorption constant $(\mathrm{L} / \mathrm{mg})$. The plot of $C_{\mathrm{e}} / q_{\mathrm{e}}$ versus $C_{\mathrm{e}}$ gives a straight line and the values of $Q^{0}$ and $b$ can be calculated from the slope and intercept of the plot, respectively.
In order to determine the feasibility of the isotherm, the essential characteristics of the Langmuir isotherm can be expressed in terms of a dimensionless constant, separation factor or equilibrium parameter, $R_{L},{ }^{47}$

$$
R_{L}=\frac{1}{1+b C_{o}}
$$

where $\mathrm{C}_{\mathrm{o}}$ and $\mathrm{b}$ are the initial fluoride concentration and Langmuir constant, respectively.

The value of $R_{L}$ indicates the type of the isotherm to be either unfavorable $\left(R_{L}>1\right)$, linear $\left(R_{L}=1\right)$, favorable $\left(0<R_{L}<1\right)$ or irreversible $\left(R_{L}=0\right)$. In the present work, the $R_{L}$ values calculated in the studied range of fluoride concentrations $\left(R_{L}\right.$ value for the fluoride concentration of $5-30 \mathrm{mg} / \mathrm{L}$ ) are determined to be in the range of $0.30-0.73$, for TNFC (virgin) and TNFC (treated), which suggests the favourable sorption of fluoride.

Freundlich equation is derived to model the multilayer sorption and for the sorption on heterogeneous surfaces. The Freundlich model is formulated as

$$
q_{e}=K_{f} C_{e}^{1 / n}
$$

where $K_{f}\left((\mathrm{mg} / \mathrm{g})(\mathrm{L} / \mathrm{mg})^{1 / \mathrm{n}}\right.$ and $1 / \mathrm{n}$ are indicators of adsorption capacity and adsorption intensity respectively, $q_{e}$ is the amount of fluoride adsorbed per unit weight of the sorbent $(\mathrm{mg} / \mathrm{g}), C_{e}$ is the equilibrium concentration of fluoride in solution $(\mathrm{mg} / \mathrm{L})$. Values of $1 / n$ are between 0.1 to 1 indicating the favorable conditions for adsorption. The values of Langmuir constants $\mathrm{Q}^{\circ}$ and $\mathrm{b}$ and Freundlich parameters $K$ and $1 / \mathrm{n}$ along with the correlation coefficients $\left(\mathrm{r}^{2}\right)$ are presented in Table 4. The maximum adsorption capacities of different adsorbents obtained from different sources are included in Table 5 along with the values obtained in the present study.

Table 4. Parameters of Langmuir and Freundlich isotherms for adsorption of fluoride on virgin and acid treated TNFC.

\begin{tabular}{|c|c|c|c|c|c|c|c|}
\hline Biosorbent & \multicolumn{3}{|c|}{ Langmuir constants } & \multicolumn{5}{c|}{ Freundlich constants } \\
\hline & $\mathrm{Q}^{0}$ & $\mathrm{~b}$ & $\mathrm{R}^{2}$ & $\mathrm{~K}_{\mathrm{f}}$ & $\mathrm{n}$ & $1 / \mathrm{n}$ & $\mathrm{R}^{2}$ \\
\hline TNFC(virgin) & 4.14 & 0.074 & 0.997 & 3.920 & 1.441 & 0.693 & 0.970 \\
\hline TNFC(treated) & 6.11 & 0.075 & 0.999 & 2.302 & 1.331 & 0.751 & 0.991 \\
\hline
\end{tabular}

Table 5. Comparison of biosorption capacities of various adsorbents for fluoride removal.

\begin{tabular}{|l|c|c|}
\hline Adsorbent & Biosorption capacity $\left(\mathrm{Q}^{0} \mathrm{mg} / \mathrm{g}\right)$ & References \\
\hline Charcoal & $7.88 \times 10^{-5}$ & {$[20]$} \\
\hline Red mud & $6.28 \times 10^{-3}$ & {$[23]$} \\
\hline Nano-alumina & 14.0 & {$[29]$} \\
\hline Waste mud & 27.2 & {$[36]$} \\
\hline Spirogyra sp- 102 & 1.27 & {$[48]$} \\
\hline Alum sludge & 5.39 & {$[49]$} \\
\hline Acid treated spent bleaching earth & 7.75 & {$[50]$} \\
\hline Pleurotus ostreatus -1804 & 1.27 & {$[51]$} \\
\hline La- incorporated chitosan beads & 4.7 & {$[52]$} \\
\hline Calcium supported carbon & 19.05 & {$[53]$} \\
\hline Alumina cement granules & 10.214 (from synthetic water) & {$[54]$} \\
\hline Granular ceramic & 12.12 & {$[55]$} \\
\hline Hydrotalcite/chitosan composite & 1.255 & Present study \\
\hline TNFC (Virgin) & 4.14 & Present study \\
\hline TNFC (Treated) & 6.11 & natural ground water) \\
\hline
\end{tabular}




\section{Effect of co-existing ions}

In field samples, a wide variety of anions like sulphates, chlorides, carbonates, bicarbonates, etc., are also present and can affect the adsorption capacity of the sorbent. To assess the suitability of TNFC for the adsorption of fluoride removal was studied in the presence of different anions. Test fluoride solution was spiked with anions at concentrations midway between permissible limits and tolerance limits stipulated for drinking water as prescribed by Bureau of Indian Standard/World Health Organization and subjected to sorption experiments. Contaminated ground water contains several other coexisting ions along with fluoride, which may compete with fluoride for the active sorption sites. However, the investigations conducted so far are with distilled water spiked with fluoride, where the concentration of other ions present is negligible.

Hence, it is important to investigate the interference of co-existing ions on fluoride sorption onto TNFC for evaluating the suitability of TNFC for field applications. Figs. 5 and 6 show the effect of various co existing ions of different concentrations on fluoride sorption by TNFC in its virgin and treated forms. It is observed from Figs. 5 and 6 that the presence of chloride ions in varying proportions has little effect on sorptive removal of fluoride by TNFC in its virgin and treated forms, i.e., reduction in sorption was only 5 to $11 \%$. Presence of sulphate exhibited appreciable effect on sorptive removal of fluoride. Sorption capacity was reduced by $37 \%$, for TNFC (virgin) and $15 \%$ for TNFC (treated).

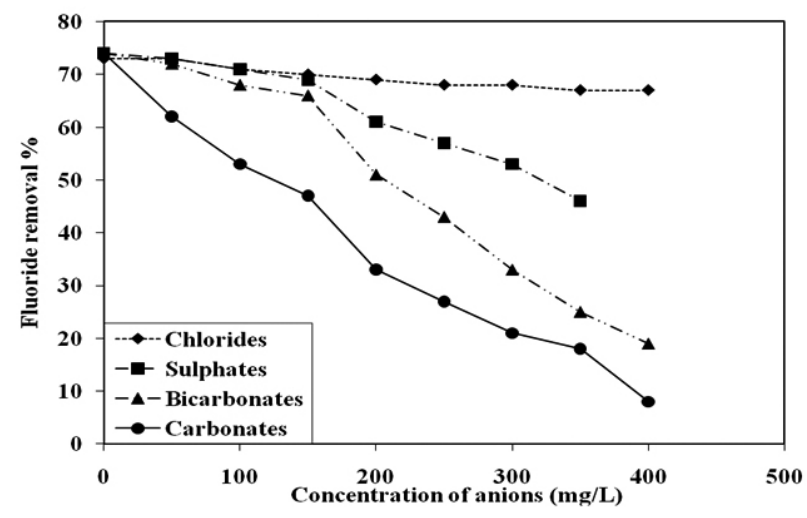

Figure 5. Effect of anions on fluoride adsorption on to TNFC (virgin)

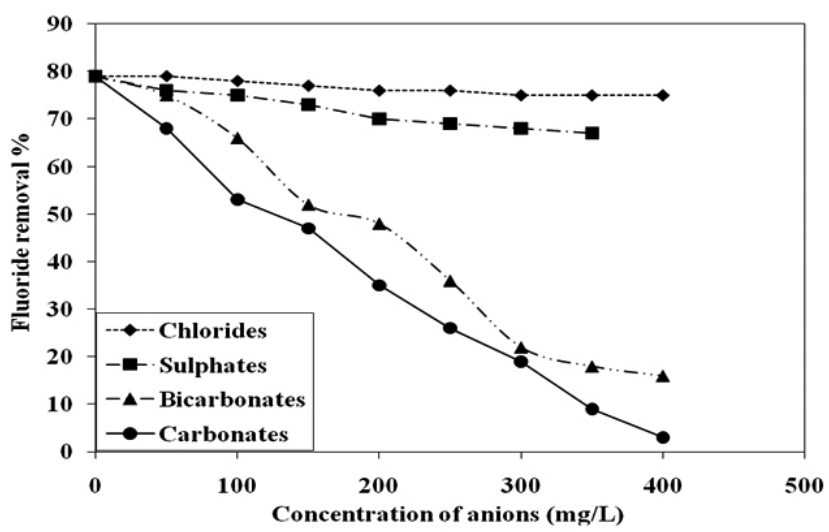

Figure 6. Effect of anions on fluoride adsorption on to TNFC (treated)

Presence of carbonate and bicarbonate had detrimental effect on sorption of fluoride and the removal efficiency was reduced drastically. Between bicarbonate and carbonates ions, carbonates had a more detrimental effect. Presence of bicarbonate reduced sorption of fluoride by $75 \%$ at a concentration of $400 \mathrm{mg} / \mathrm{L}$ where as the presence of carbonate ions reduced sorption of fluoride by maximum of $96 \%$.

It thus follows that anions especially, carbonate and bicarbonates has considerable influence on sorptive removal of fluoride and this is due to competition and preferential sorption of these anions in comparison to fluoride ions. The reduction in fluoride removal observed by the presence of $\mathrm{SO}_{4}{ }^{2-}$,
$\mathrm{HCO}_{3}^{-}$and $\mathrm{CO}_{3}{ }^{2-}$ may be due to competition from these ions for active sorption site or due to the change in $\mathrm{pH}$ or combination of these two.

\section{Column adsorption studies}

Column adsorption studies of fluoride on TNFC in its virgin and treated forms at room temperature $\left(25 \pm 1^{\circ} \mathrm{C}\right)$ are investigated using aqueous solution at $10 \mathrm{mg} / \mathrm{L}$ influent concentration (C), at optimum $\mathrm{pH}$ value. The breakthrough curve for a column is determined by plotting (figures not shown) the ratio of the $\mathrm{C}_{\mathrm{e}} / \mathrm{C}_{0}\left(C_{\mathrm{e}}\right.$ and $C_{0}$ are the fluoride concentration of effluent and elluent, respectively) against the volume of elluent solution. The data are obtained by passing the fluoride solution through a bed with $3 \mathrm{~g}$ of adsorbents in a downward flow at a rate of $2 \mathrm{~mL} / \mathrm{min}$ and determining the concentration of fluoride at different time intervals in the effluent solution. These curves followed the typical S-shaped for column operation with favorable adsorption. When the column gets saturated, it is generated and subsequently used for next adsorption process. The adsorption- desorption cycles are repeated thrice.

\section{Desorption studies}

The regeneration of the sorbent can be accomplished by a variety of techniques such as thermal desorption, steam washing, solvent extraction etc. Each method has inherent advantages and limitations. In this study several solvents are tried to regenerate the TNFC adsorption bed. $0.1 \mathrm{M} \mathrm{NaOH}$ solution was found to be effective in desorbing and removing fluoride ion quantitatively from the adsorbent bed. The fixed bed columns of adsorbents saturated with fluoride solution are regenerated by passing $0.1 \mathrm{M} \mathrm{NaOH}$ solution as an eluent at fixed flow rate of $1.0 \mathrm{~mL} / \mathrm{min}$. More specifically, maximum desorption (figures not shown) occurs at $100 \mathrm{~mL}$ of $0.1 \mathrm{M} \mathrm{NaOH}$ solution and complete regeneration of fluoride occurs at $150 \mathrm{~mL}$.

Biosorption with real field water samples

In order to gauge the practical utility of the TNFC (treated) as an adsorbent for fluoride removal, batch studies were performed to evaluate its viability for real field water samples. In the present study the field samples were collected from twelve ground water samples from fluoride affected areas of Anantapur District, Andhra Pradesh, India, having high concentrations of fluoride was collected and biosorption studies were performed subsequently. Ground water samples were collected in plastic bottles from bore wells/dug wells in the fluoride affected villages of various mandals. The collected field water samples were analyzed and the data was presented in Table 6.

Anantapur District is in the Southwestern corner of Andhra Pradesh state. The District has 964 revenue villages included in 63 mandals. There are 1491 habitations with more than $1.5 \mathrm{mg} \mathrm{L}^{-1}$ of fluoride concentration in drinking water distributed in all the 63 mandals in Anantapur District. Among the those mandals in Anantapur District, the worst affected areas of fluorosis are Kadiri, Dharmavaram, Raptadu, Anantapur, Mudigubba, Nallamada, Gooty, Gorantla and Palavai. The biosorption experimental data of real field water samples by using treated TNFC results are presented in Table 7. From these observations, it can be concluded that the adsorption capacity of the TNFC adsorbent is decreased, when applied to real field water samples compared to synthetic samples. This may be due to the initial fluoride ion concentrations, $\mathrm{pH}$ and presence of co-existing anions in the field samples.

\section{CONCLUSIONS}

The results obtained in the present study showed that the tamarind fruit cover in its natural and acid treated forms could be used as a potential biosorbing agent for the removal of fluoride ions from an aqueous media. The maximum uptake of fluoride ions occurs at $\mathrm{pH}$ 6.0. An increase in the amount of biosorbent increased the percentage removal of fluoride ions. Furthermore, the biosorbent was characterized by FTIR spectroscopy, porosity and scanning electron microscopy (SEM) techniques. The kinetic studies indicated that the sorption of fluoride on TNFC in both natural and acid treated forms followed pseudo-second-order kinetic model. The data obtained fit well to both the Langmuir and Freundlich isotherms and the maximum monolayer biosorption capacities of TNFC in both natural and acid treated forms are found to be $4.14 \mathrm{mg} / \mathrm{g}, 6.11 \mathrm{mg} / \mathrm{g}$, respectively, at $25 \pm 1^{\circ} \mathrm{C}$ according to Langmuir model. Column adsorption and desorption experiments showed that it is possible to remove the bound fluoride ions to regenerate the adsorbent. Results of this investigation proved that TNFC in its virgin and acid treated forms is a suitable alternative for the removal of fluoride ions from aqueous media compare to other bioadsorbents. 
Table 6. Analysis of real field water samples.

\begin{tabular}{|c|l|l|c|c|c|c|c|c|c|c|c|}
\hline S.No. & Name of the village ${ }^{a}$ & $\begin{array}{c}\text { Name of the } \\
\text { mandal }^{\mathrm{a}}\end{array}$ & $\mathrm{pH}$ & $\begin{array}{c}\mathrm{TDS} \\
\mathrm{mg} / \mathrm{L}\end{array}$ & $\begin{array}{c}\mathrm{CO}_{3}^{2-} \\
\mathrm{mg} / \mathrm{L}\end{array}$ & $\begin{array}{c}\mathrm{HCO}_{3}^{-} \\
\mathrm{mg} / \mathrm{L}\end{array}$ & $\begin{array}{c}\mathrm{F}^{-} \\
\mathrm{mg} / \mathrm{L}\end{array}$ & $\begin{array}{c}\mathrm{Cl} \\
\mathrm{mg} / \mathrm{L}\end{array}$ & $\begin{array}{c}\mathrm{Ca} \\
\mathrm{mg} / \mathrm{L}\end{array}$ & $\begin{array}{c}\mathrm{Mg} \\
\mathrm{mg} / \mathrm{L}\end{array}$ & $\begin{array}{c}\mathrm{Na} \\
\mathrm{mg} / \mathrm{L}\end{array}$ \\
\hline 1 & Mulakalacharuvu & Kadiri & 7.8 & 440 & 0 & 500 & 1.9 & 227 & 92 & 51 & 69 \\
\hline 2 & T.Kottapalli & Gotty & 7.5 & 651 & 0 & 305 & 3.2 & 135 & 88 & 56 & 99 \\
\hline 3 & Raptadu & Raptadu & 7.7 & 280 & 0 & 244 & 4.0 & 241 & 83 & 48 & 320 \\
\hline 4 & Palacherla & Raptadu & 8.1 & 100 & 0 & 708 & 3.0 & 241 & 16 & 15 & 416 \\
\hline 5 & Iragarajupalli & Puttaparti & 7.6 & 410 & 0 & 586 & 2.4 & 411 & 100 & 39 & 437 \\
\hline 6 & RallaAnatapuramTanda & Mudigubba & 8.2 & 280 & 0 & 891 & 2.6 & 482 & 40 & 43 & 414 \\
\hline 7 & Varli & Kalyanadurgam & 7.6 & 315 & 0 & 275 & 3.5 & 184 & 27 & 68 & 99 \\
\hline 8 & Sanapa & Atmakur & 8.8 & 523 & 9 & 521 & 1.8 & 284 & 79 & 25 & 98 \\
\hline 9 & Gopepalle & Nallamada & 7.7 & 180 & 0 & 598 & 2.6 & 191 & 32 & 24 & 285 \\
\hline 10 & Kanukuru & Setturu & 7.6 & 340 & 0 & 598 & 3.0 & 206 & 48 & 54 & 251 \\
\hline 11 & Balavenkatapuram & Kalyanadurgam & 7.8 & 120 & 0 & 574 & 3.2 & 99 & 20 & 17 & 202 \\
\hline 12 & Chintalaiahgaripalli & Bukkapatnam & 7.9 & 350 & 0 & 590 & 2.6 & 461 & 68 & 44 & 499 \\
\hline
\end{tabular}

${ }^{a}$ Anantapur District, Andhra Pradesh, India.

Table 7. Experimental data of biosorption of real field water samples using treated TNFC.

\begin{tabular}{|c|c|c|c|c|c|c|}
\hline \multirow{2}{*}{ Sample No } & Village & $\mathrm{pH}$ & $\begin{array}{c}\text { Fluoride concentration in } \\
\text { sample water (mg/L) }\end{array}$ & $\begin{array}{c}\mathrm{C}_{\mathrm{e}} \\
(\mathrm{mg} / \mathrm{L})\end{array}$ & $\%_{\text {removal }}$ & $\begin{array}{c}\mathrm{Q}_{\mathrm{e}} \\
(\mathrm{mg} / \mathrm{g})\end{array}$ \\
\hline 1 & Mulakalacharuvu & 7.8 & 1.9 & 1.5 & 21.0 & 0.04 \\
\hline 2 & T.Kottapalli & 7.5 & 3.2 & 2.2 & 31.2 & 0.10 \\
\hline 3 & Raptadu & 7.7 & 4.0 & 2.5 & 37.5 & 0.15 \\
\hline 4 & Palacherla & 8.1 & 3.0 & 2.3 & 23.3 & 0.07 \\
\hline 5 & Iragarajupalli & 7.6 & 2.4 & 1.8 & 25.0 & 0.06 \\
\hline 6 & RallaAnatapuramTanda & 8.2 & 2.6 & 1.6 & 38.4 & 0.10 \\
\hline 7 & Varli & 7.6 & 3.5 & 1.5 & 57.1 & 0.20 \\
\hline 8 & Sanapa & 8.8 & 1.8 & 1.3 & 27.8 & 0.05 \\
\hline 9 & Gopepalle & 7.7 & 2.6 & 1.8 & 38.4 & 0.10 \\
\hline 10 & Kanukuru & 7.6 & 3.0 & 1.8 & 40.0 & 0.12 \\
\hline 12 & Balavenkatapuram & 7.8 & 3.2 & 1.5 & 42.3 & 0.14 \\
\hline
\end{tabular}

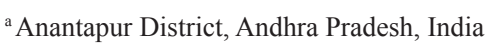

\section{REFERENCES}

1. WHO (World Health Organization), Guidelines for Drinking Water Quality Health criteria and other supporting information, Vol. 2, $2^{\text {nd }}$ ed: World Health Organization, Geneva, 1997.

2. D. Sarala kumari, P. Ramakrishna Rao, Fluoride. 26, 177, (1993)

3. D. Raja Reddy, Hand book of Neurology, North Holland publishing Co: Amsterdam; p. 465, 1979.

4. S. C. Freni, J. Toxicol. Environ. Health. 42, 109, (1994)

5. R. Tekle-Haimanot, Z. Melaku, H. Kloos, C. Riemann, W. Fantaye, L. Zerihum, K. Bjorvatn, Sci Total Environ. 367, 182, (2006)

6. USPHS (United State Public Health Service), Drinking Water Standard-1962, USPHS, Publication 956, USGPO, Washington, DC. 1962.

7. W. R. Lesan, E Afr Med J. 64, 493, (1987)

8. A. Ababa, Federal Democratic Republic of Ethiopia, Ethiopian quality and Standard Authority Guidelines for Drinking Water Quality, 2001.

9. Q. Zhang, H. Liang, Environ. Int. 18, 307, (1992)

10. S. S. Tripathy, A. M. Raichur, J. Hazard. Mater. 153, 1043, (2008)
11. E. Oguz, J. Hazard. Mater. B117, 227, (2005)

12. E. I. Reardon, Y. X. Wang, Environ. Sci. Technol. 34, 3247, (2000)

13. Z. Amor, B. Bernard, N. Mameri, M. Taky, S. Nicolas, A. Elmidaoui, Desalination. 133, 215, (2001)

14. C. Castel, M. Schweizer, M. O. Simonnot, M. Sardin, Chem. Eng. Sci. 55, 987, (2000)

15. F. Shen, X. Chen, P. Gao, G. Chen, Chem. Eng. Sci. 58, 3341, (2003)

16. N. Mameri, A. R. Yeddou, H. Lounici, D. Belhocine, H. Grib, B. Bariou, Water Res. 32, 1604, (1998)

17. X. D. Fan, J. Parker, M. D. Smith, Water Res. 37, 4929, (2003)

18. A. K. Chaturvedi, K. P. Yadava, K. C. Pathak, V. N. Singh, Water Air Soil Pollut. 49, 51, (1990)

19. R. Wang, H. Li, P. Na, Y. Wang, Water Qual Res J Canada. 30, 81, (1995)

20. D. S. Bhargava, D. J. Killedar, Water Res. 26, 781, (1992)

21. Y. D. Lai, J. C. Liu, Sep Sci Technol. 31, 2791, (1996)

22. S. Mayadevi, Indian Chem Eng. A38, 155, (1996)

23. Y. Cengeloglu, E. Kir, M. Ersoz, Sep. Purif. Technol. 28, 81, (2002)

24. M. Srimurali, A. Pragathi, J. Karthikeyan, Environ Pollut. 99, 285, (1998)

25. G. Moges, F. Zewge, M. Socher, J Afr Earth Sci. 21, 479, (1996) 
26. K. Bjorvatn, C. Reimann, S. H. Ostvold, R. Tekle-Haimanot, Z. Melaku, U. Siewers, Oral Health Prev Dent. 1, 141, (2003)

27. E. Kumar, A. Bhatnagara, U. Kumar, M. Sillanpaa, J. Hazard. Mater. 186, 1042, (2011)

28. V. Gannvir, K. Das, J. Hazard. Mater. 185, 1287, (2011)

29. B. Kemer, D. Ozdes, A. Gundogdu, V. N. Bulut, C. Duran, M. Soylak, J. Hazard. Mater. 168, 888, (2009)

30. B. Shimelis, F. Zewge, B. S. Chandravanshi, Bull Chem Soc Ethiop. 20, 17, (2006)

31. E. Dahi, F. Mtalo, B. Njau, H. Bregnhj, Defluoridation using the Nalgonda Technique in Tanzania, In: Proceedings of the $22^{\text {nd }}$ WEDC Conference, New Delhi, India, 1996.

32. V. Sivasankar, T. Ramachandramoorthy, A. Chandramohan, J. Hazard. Mater. 177, 719, (2010)

33. S. Srimachari, Arogya. 6, 617, (1983)

34. M. Maruthamuthu, J. Venkatanarayana Reddy, Fluoride. 20, 109, (1987)

35. Y. Vijaya, S. R. Popuri, A. Subba Reddy, A. Krishnaiah, J Applied poly Sci. 120, 3443, (2011)

36. S. Venkata Mohan, S. V. Ramanaiah, B. Rajkumar, P. N. Sarma, J. Hazard. Mater. 141, 465, (2007)

37. S. R. Popuri, J. Ajithapriya, N. S. R. Kachireddy, A. Krishnaiah, Electron. J. Biotech. 10, 358, (2007)

38. S. Meenakshi, P. Anitha, G. Karthikeyan, B. V. Appa Rao, Indian. J. Environ. Protec. 7, 511, (1991)

39. G. Karthikeyan, A. S. Sundarraj, S. Meenakshi, K. P. Elango, J Indian Chem Soc. 81, 461, (2004)
40. A. M. Raichur, M. J. Basu, Sep. Purif. Technol. 24, 121, 2001.

41. M. S. Maliyekkal, S. Sanjay, P. Ligy, M. N. Indumathi, Chem Eng. J. 140, $183,(2008)$

42. S. Lagergren, Handlingar, Band. 1, 24, (1898)

43. Y.S. Ho, Scientometrics. 59, 171, (2004)

44. Y. S. Ho, G. McKay, Chem Eng. J. 70, 115, 1998.

45. W. J. Weber, J. C. Morriss, J. Sanit. Eng. Div. Am. Soc. Civ. Eng. 31, 89, (1963)

46. C. Namasivayam, R. T. Yamuna, Environ. Pollut. 1, 89, (1995)

47. K. R. Hall, L. C. Eagleton, A. Acrivos, T. Vermeulen, Ind. Eng. Chem. Fundam. 212, 5, (1966)

48. M. G. Sujana, R. S. Thakur, S. B. Rao, J. Colloid. Interface. Sci. 206, 94, (1998)

49. M. Mahramanlioglu, I. Kizilcikli, I. O. Bicer, J. Fluorine. Chem. 115, 41, (2002)

50. S. V. Ramanaiah, S. Venkata Mohan, P. N. Sarma, J. Ecol. Eng. 31, 47, (2007)

51. D. Thakre, S. Jagtap, A. Bansiwal, N. Labhsetwar, S. Rayalu, J. Fluorine. Chem. 131, 373, (2010).

52. E. Tchomgui-Kamga, E. Ngameni, A. Darchen, J. Colloid. Interface. Sci. 346, 494, (2010)

53. S. Ayoob, A. K. Gupta, Chem Eng. J. 150, 485, 2009.

54. N. Chen, Z. Zhang, C. Feng, N. Sugiura, M. Li, R, Chen, J. Colloid. Interface. Sci. 348, 579, (2010)

55. N. Viswanathana, S. Meenakshi, Appl. Clay. Sci. 48, 607, (2010) 